\title{
Racism and English Language Learning: Employing an Anti- Racist Approach to English as an Additional Language Education
}

\author{
By Lisa Olding
}

\section{Introduction}

As a White, middle-class, monolingual female who speaks a Standard form of English, I often wonder what I can add to a discussion about race and English language learning. I have never experienced racism, and I have never had to learn a language to survive or prosper in a new culture. I come from a background of privilege and often expect that privilege to follow me wherever I go. On a recent trip to Amsterdam, it wasn't until I was on the airplane over the Atlantic that I considered the possibility that I may need to know a few Dutch phrases to communicate while away. I expected to be able to get by with English. After all, English is a 'global language', isn't it?

Bourdieu (1986) theorized about power, its accumulation, and its potential for profitability in his sociological conceptions of capital. When examining Bourdieu's early works on forms of capital, language seems to fit into the category of cultural capital. When viewed in this way, language becomes an element that can contribute to or detract from one's identity and social standing, as certain forms of language are valued over others. Bourdieu (1991) eventually gives language a sub-category of its own: linguistic capital - the ability to produce utterances for a particular market (p. 18). Linguistic capital gives its possessors an advantage to assert symbolic power over others, provided the speakers are using what are seen as the correct words, grammar, tone, and body language for the situation in which they find themselves. Often, linguistic capital is transmitted from parent to child, but increasingly, and especially in the case of the English language, it is transmitted through formal education.

Around the world, there is a growing number of linguistically diverse students enrolling in schools with English as the medium of instruction, and most educators are "interacting on a daily basis with learners with backgrounds and experiences different from his or her own" (Dei, 1996, p. 9). Diverse language groups have been present in Canada since before its inception as a European colony. From the cultural genocide of Indigenous Peoples to the fight for recognition by founding peoples, language issues have been fraught with racism from early times. It is important to acknowledge that I employ the definition of racism "as historic and systemic inequality", rather than an individual prejudice (Srivastava, 2007, p. 300). According to an article in the Vancouver Sun newspaper, English language learners (ELLs) made up eleven percent of the students enrolled in public schools in British Columbia during the 2013/2014 school year; in some schools, they accounted for over fifty percent of the student population (Skelton, 2014). Many of these students who speak a language other than English at home are Canadian-born or naturalized citizens. However, they are often portrayed as 'the Other' (or immigrants) because of the hierarchical categories of native and nonnative speaker. As a result, they face varying levels of racism and linguicism (i.e., discrimination based on a person's use of language). Phillipson (1992), as quoted in Liggett (2014), states, "linguicism has taken over from racism as a more subtle way of hierarchizing social groups in the contemporary world" (p. 113). 
Warburton (2007) identifies that as early as 1963, work was being done through the Royal Commission on Bilingualism and Biculturalism (the Bi-Bi Commission) to recognize the contributions of diverse groups to the settlement of Canada. The Bi-Bi Commission advocated for "the integration of immigrants rather than their assimilation" (Warburton, 2007, p.277), and "the federal government designed the multicultural policy to redefine Canada symbolically and to redistribute social status among linguistic and ethnocultural groups" (p. 278). As the policy was further developed, the aims of helping members of ethnocultural groups overcome barriers and acquire one of Canada's official languages were elucidated. However, it appears much of this policy has become simply symbolic. Srivastava (2007) points out "multiculturalism has been particularly important in propping up the representation of Canada as a tolerant, diverse nation, benevolent to newcomers" (p. 294). By examining current practices in contemporary Canada, it is clear the multicultural policy has achieved only minimal success. Linguistically diverse people continue to face barriers to employment and full participation in society as shown by Li's (1988) study cited in Warburton (2007): "the policy failed to combat racism or discriminatory practices in the labour market" (p. 283). In addition, while assistance is given for language learning through taxpayer-funded language classes, it sometimes comes too late as participants must attain permanent residency first, and the curriculum reinforces settler-colonial discourses. Deep analysis shows multiculturalism does not promote equity or challenge racism; instead, multiculturalism highlights difference and diversity creating an idealized, White "Canadian-Canadian" (Srivastava, 2007, p. 295). Guided in part by Srivastava's (2007) pedagogical questions about "how we learn racist knowledge, how we perpetuate racist practices, and how we can change our everyday practices" (p. 306), this paper uses ideas from critical race theory (CRT), Dlamini's (2002) interpretation of critical pedagogy, and Dei's (1996) principles of antiracism education to examine the intersection of racism and language, especially in relation to ELLs in Canadian K-12 schools.

\section{Racism and Language}

According to Dei's (1996) second principle of anti-racism of education, it is impossible to fully comprehend the social effects of race without an understanding of the intersectionality between race and other forms of social oppression. One of these forms of oppression is linguicism. It is important to view the experiences of ELLs through an intersectional framework "so that intra-group experience is recognizable and differential treatment between various linguistic groups [becomes] apparent" (Liggett, 2014, p. 119). Other areas of possible oppression that may intersect with language include immigration status, gender, and religion. Not all ELLs face the same types or levels of linguicism and/or racism. Armstrong and $\mathrm{Ng}$ (2005) are clear that "racism takes different forms across time and space in relation to groups of people" (p. 36). ELLs who are (or appear) White often face less discrimination than those who are part of a visible-minority group. Similarly, individuals who appear 'different' (i.e. a visible-minority) from the dominant Euro-Canadian society may face linguicism even when they are not ELLs. This concept is pointed out by Bannerji (1996): "all white people, no matter when they immigrate to Canada or as carriers of which European ethnicity, become invisible and hold a dual membership in Canada, while others remain immigrants generations later" (p. 13). She goes on to explain, "racism makes sure that the possession of this language [English] as a mother tongue does not make a non-white person non-ethnic" (Bannerji, 1996, p. 13). These ideas are seen in practice when a person who is a native English speaker and also a visible-minority encounters surprised comments such as 'your English is so good' during 
daily interactions. The English language is not a neutral entity that can be equally claimed by all people. As a result, both native speakers and ELLs who belong to a visible-minority group often face oppression.

Dei's (2006) third principle brings Whiteness and the associated privilege and power into question. It is necessary to examine the societal and systemic forces at work in the context of White privilege and power in relation to the English language. The fact that society inherently associates the English language with Whiteness means ELLs who are White are afforded more agency than those who are visible-minorities; they commonly have the power to make choices in society that are not afforded to native English speakers who are visibleminorities. Often, White ELLs have the agency to bend the rules of language or misspeak without facing the same judgment their visible-minority peers may encounter. Stanley (2006) explains a similar phenomenon that occurs in university faculties: "many faculty of colour perceived that higher expectations were held of them, ... and as such they had 'to prove and "overprove" their presence and worth in the academy' to their White colleagues" (as cited in James, 2009, p. 146). When people of colour speak English, they must prove their legitimacy.

Racism can influence the way people view the English language. One problematic concept in English language learning is the categorization of people as native English speakers (NS) and non-native English speakers (NNS). Most learners (and people in general) perceive the NS category as more desirable and work hard to remove any hint of accentedness that would point to their status as an ELL. Another language concept closely related to racism is the concept of 'Standard English'. Just as "race ... is a purely imaginary social fabrication for the purpose of establishing a hierarchy among people" (Armstrong \& Ng, 2005, p. 35), so is the concept of Standard English. Coelho (1998) defines Standard English as the dialect "which is spoken by those in authority and those with education, and is usually the most widely accepted and understood in the society at large" (p. 88). While 'standard' and 'correct' are not synonymous, there is significant linguistic and cultural capital granted to those who use Standard English.

Dei's (1996) fourth principle is directly related to the marginalization of certain voices in English. Fighting the societal expectation that NS's are White requires people to confront systemic practices and hegemonic power structures that have existed for centuries. Standard English is a result of hegemony - one dominant group prescribes the acceptable form of communication for other subordinate groups; as such, Standard English becomes "the common sense thinking and practices of the masses, although these ideas may have originated from the dominant classes" (Armstrong \& Ng, 2005, p. 43). The concept of Standard English clearly links to colonialism - the expansion of the English language accompanied the expansion of the British Empire. I believe it is impossible to analyze the implicit connection between Whiteness and NS without also examining the global impact of colonialism. Taylor (2006) states, "British imperialism ... promoted English as a language of global economic and cultural power, of Whiteness and epistemological authority" (p.523). Lee (2015) argues that the native/non-native speaker categories in applied linguistics as well as the ideas of Standard English and accentedness must be examined through a lens of race and racialization. All of these categorizing concepts have the potential to ensnare ELLs with a perpetual label of 'Other' resulting in their marginalization; Young (1990) claims this fate is potentially "the most dangerous form of oppression" due to the eventual material deprivation and threat of extermination (p. 53). 
In order for ELLs to have equity, those with privilege must question the supposed hierarchy of the NS and the fabricated norms of Standard English. What privileges one form of English over another and who decides? Kubota (2015) asserts, "who is the legitimate speaker and who is not is determined through forms of symbolic violence" (p.9). Symbolic violence is when the values of the ruling class are imposed upon the dominated social class. Implementing Dei's third and fourth principles of anti-racism education requires a change of attitude that will value all speakers of English regardless of their skin colour and/or accentedness.

From this discussion, it should be clear that racism and language have numerous points of intersection. Ideas like colonialism and hegemony are seen repeatedly in slightly different iterations. Capital, privilege, and ethnicity all play a role in the linking of racism and language. In keeping with the idea from CRT that racism is "normal, not aberrant, in American [and Canadian] society", the task, when considering language, is to expose the places and forms in which racism exists (Delgrado, 1995, p. xiv as cited in Ladson-Billings, 1998, p. 11). One of those places is the language classroom.

\section{Racism in Language Teaching and Learning}

Racism has a long-standing history with English language teaching and learning. Historically, as the British Empire spread, the number of English learners increased. Although there is currently greater acceptance of linguistic diversity, at one time, the goal of teaching English as an Additional Language (EAL) was to create proper British citizens who would speak Standard English. When education takes an assimilationist approach towards language, it is stating that diversity is a problem. Racism also has a long-standing history with schooling in general. Dlamini (2002) explicates this issue, stating "the racism of the last decades is ... more structurally entrenched in the economic system since the globalization of capital has led to structures that are often not recognised as racist. School is one such structure ..." (p. 54). Canada purports to encourage diversity and 'multiculturalism', but when it comes to language and schooling, assimilation seems to be not only the historical but also the current norm.

In Canada, residential schools were operated to eliminate Aboriginal culture and included an emphasis on modifying language. Children were not allowed to speak their languages and often faced harsh punishments if they disobeyed. The assimilation policies were catastrophically effective as Aboriginal peoples faced extreme "cultural loss in the aftermath of colonial violence that deliberately targeted language and customs" (Henderson \& Wakeham, 2013, p. 17). As a result, many Aboriginal languages were lost and others are on the verge of extinction. This too is an intersecting point of racism and language, yet many people do not recognize it as such. In Armstrong and $\mathrm{Ng}$ (2005), Jeannette Armstrong makes this argument eloquently when she states, "what is appalling is that nobody thinks it is racism when a native person stands up and speaks his or her language and no one understands a single word. Who decided that my language isn't valuable?” (p. 33). The modern school system has made limited attempts to include Aboriginal language and culture in its current discourse and practice; continued attention and effort needs to be focused on this matter.

Coelho (1998) mentions a Canadian educator, Black, who wrote in 1913 "the wisest method of teaching English will aim at eliminating for the time being from the learner's consciousness all memory or thought of his vernacular tongue” (p. 20). While some language 
teachers now recognize the need to encourage students to maintain their heritage language as they learn English, many continue to assert an English-only policy that serves to weaken the learners' first language (L1) abilities. This practice is a racist approach to language learning. Students do not come as a tabula rasa, or blank slate. They come into classrooms with identities and cultures that are often explicitly connected to their language. By forcing students to give up their L1, the teacher is devaluing their culture and identity and requiring students to do the same. In addition, an English-only policy removes the opportunity for beginners to demonstrate their competency through the bridging and scaffolding of their L1.

EAL education continues to be linked to colonialist systems. Taylor (2006) claims, "Historical processes of imperialism and racism are not incidental to our field [TESOL], but rather, central to its discursive and material practices" (p.523). There remains a hidden curriculum of assimilating ELLs into Canadian (White) culture. Dei (1996) points out problems with elevating the knowledge and experience of some groups over others, and states, "through the school's curriculum, educators and students are provided with academic definitions of what counts as valid knowledge" (p. 21). ELLs often find themselves in classrooms where their cultural backgrounds and ways of knowing are not validated. In addition, consistent and repeated classroom discourse about cultural differences between students' culture of origin and Canadian culture socializes ELLs into an identity of 'Otherness'. ELLs may even find themselves developing a “double consciousness' - this sense of always looking at one's self through the eyes of others" (Du Bois, 1969 [1903], p. 45, as cited in Young, 1990, p. 60). Students can maintain their identity in their L1 culture, but also find themselves being defined in terms of the dominant English culture as they battle colonialist discourse.

ELLs can struggle against the push for assimilation by keeping their culture and knowledge central to classroom curriculum. Ladson-Billings (1998) warns that "members of minority groups internalize the stereotypic images that certain elements of society have constructed" (p. 14). For this reason, the stories of individual students should be included in classrooms. However, Smith (2010) points out "there is much at stake in how stories are told, by whom, and whether and how they historicize, contextualize, and explain equity and existing social relations" (p. 43). Narratives and storytelling are a central aspect of Critical Race Theory. Teachers need to help their students learn to tell their stories in ways that problematize common stereotypes. By sharing counternarratives, ELLs are able to take back the role of expert, gain power, and have some control over the construction of knowledge in their classroom.

In addition, EAL textbooks often provide stereotypical White examples that reinforce the colonial discourses present in Canada. Kubota and Lin (2006) note that the "Hegemony of Whiteness is also reflected in ESL/EFL textbooks when constructing the norm with regard to what is legitimate linguistic and cultural knowledge" (p. 479). By recognizing certain forms of knowledge in the official curriculum and its supporting materials, students' identities are likely undermined. Not only is the content of ELL racially loaded, but also "our practice of TESOL is never neutral but always embedded within racialised and imperialist ... discourses that our pedagogy might either perpetuate or challenge" (Taylor, 2006, p. 540). The language that EAL instructors use when communicating with students and the activities they plan can promote colonial ideals and challenge learner identity. Because of its connection to colonialism and assimilation, learning English can be a negative experience for many ELLs. 
As mentioned previously, one can see racism at work when accepted varieties of English are analyzed. Who decides what variety passes as Standard English? Bannerji (1996) further troubles this idea when she points out:

Marginalizing the ethnicity of black people from the Caribbean or Britain is evident ... in their being forced to take English as a second language. They speak dialects, it is said - but it might be pointed out that the white Irish, the white Scots, or the white people from Yorkshire, or the white Cockney speakers are not classified as [EAL] clients. (p. 13)

A similar idea is presented in a book by Coelho (1998). In a section titled Learning Standard English (p. 87-89), Coelho (1998) appears to advocate for an anti-racist approach by problematizing instances when speakers of Black English Vernacular and other varieties of English are judged as "careless, lazy, or of limited intellectual capacity" by teachers who are uninformed about language variety (p. 88). Dei (1996) also discusses concerns about the placement of Black students in English skills development classes even though they selfidentify as speakers of English (p. 91). Coelho (1998) encourages educators to "recognize and validate the linguistic systems that students bring to school" and claims all "varieties of languages should be viewed as equally valid forms of communication" (p. 88). Nonetheless, she maintains, "it is the function of the school to help all students to develop proficiency in standard English" (Coelho, 1998, p. 88). In addition, the language of success, the Standard English of a NS, is generally viewed as White. How can a school help students access the forms of English that bring capital and power without inadvertently socializing students into a culture of shame due to the belief that their accent or dialect is substandard? In contrast to the idea that students should be guided to adopt the more socially acceptable Standard English, Dei (1996) discusses the practice of African-centred schools where "the use of students' languages and dialects is encouraged as an effective pedagogical tool for academic success" (p. 114). Mainstream schools are perpetuating the hierarchy of Standard English through their practices, and better options for equity exist.

Not only do ELLs face racism and linguicism, but so do EAL teachers. When it comes to being hired as a language teacher, "native speakers of English have a privileged status in employment, a privilege that is increased by having White skin" (Kubota \& Lin, 2006, p. 479). Because of the hierarchy of NS over NNS, teachers who 'look' more like NS (i.e. White) are often more likely to be hired for EAL positions (Motha, 2014, p. 5). Again, Dei's (1996) third principle comes into effect. Why do these powerful societal forces continue to privilege White NS EAL teachers? In addition, this principle provides "an entry point for members of dominant groups in society to join the anti-racism debate" as they question their own White power and privilege (Dei, 1996, p. 28).

Many students and teachers accept Linguicism as a normal part of life. Often, ELLs are required to complete the same work and write the same tests as their NS peers before they have gained sufficient academic proficiency in English and without support or scaffolding. According to Cummins (2002) it takes ELLs approximately five years on average to attain grade level academic English. These constructs favour NS students and result in increasing failure rates among ELLs. The results of many assessments do not show content knowledge, but English ability (Liggett, 2014). It is necessary to reveal these sorts of policies and procedures as inherently racist. English-only policies that disallow the use of L1 instruction to 
aide in English acquisition maintain contemporary colonialism by implying that English is superior to other languages. This practice demonstrates a deficit model of education: "When we frame the universe of discourse primarily in terms of culturally diverse students' deficits in standard English, we expel culture, bilingualism, identity, intellect, and imagination from our image of the child" (Cummins, 2002, p. 29). Dei's (1996) fourth principle problematizes this sort of model. Instead, he calls for the dominant culture to create spaces for the marginalized groups to be heard. To achieve this goal, EAL educators must implement an anti-racism education approach in their classrooms and schools.

\section{EAL and Anti-racism Education}

Dei (1996) defines anti-racism education "as an action-oriented strategy for institutional, systemic change to address racism and the interlocking systems of social oppression" (p. 25). He seeks to broaden the definition of racism to include issues of power and equity and not simply matters of cultural and ethnic variety. There is a need for teachers to develop "students' capacities to analyze and act on the ways all forms of discrimination/privilege ... interlock in everyday interactions" (Taylor, 2006, p. 524-525). How can this task be achieved? Partly through explicit anti-racism education.

Critical pedagogy and anti-racism education are fundamentally about helping students develop their consciousness and recognize that "as presently conceived, the education system does not serve the interest of minority groups" (Dlamini, 2002, p. 54). Ladson-Billings (1998) also asserts there is a "need to make racism explicit so that students can recognize and struggle against this particular form of oppression" (p. 19). By giving students the language to analyze their own experiences, they will be better equipped and may be more likely to stand up against future forms of discrimination and racism.

Another aspect of anti-racism teaching is making students aware of opportunities to investigate and carry out social justice activities. Dei (1996) posits that "educators have the responsibility to bring to their students' attention social injustice and how everyone is implicated in the fight for justice and human dignity ... the duty to let all students be aware of the racial, class, gender and sexual implications of whatever is taught. They have a duty to teach about the scourge of racism, sexism, classism and other forms of social oppression" (p. 17). This duty extends to all students, whether NS or ELL. Implementing change in the entire school community can help reduce the instances of racism and oppression faced by ELLs. There is also a need to employ critical pedagogies to "explicitly engage teachers and students in dialogues on relations of power with regard to race, gender, class, and other social categories" (Kubota \& Lin, 2006, p. 485). Students and teachers must be able to analyze a teaching activity or situation and discern areas of discrimination, and "to recognize and question forms of discrimination they had previously accepted as natural or exceptional" (Taylor, 2006, p. 539). It is necessary to help students identify the hidden curriculum of EAL (i.e., the idealized English speaker is White) and identify areas of racism and social injustice they face in other classes.

Anti-racist EAL pedagogy must be more than potluck lunches and dress-up days like the criticized 3-D approach "that celebrates dance, dress, and dining" (Srivastava, 2007, p. 291). Kubota and Lin (2006) also call for EAL teachers to move away from a "difference-blind egalitarian vision about diverse cultures and peoples, [and a] perpetuation of the exotic and 
romanticized Other through celebrating superficial aspects of cultural difference (i.e., the heroes and holidays approach)" (p. 485). Using intersectionality to examine racism and linguicism allows teachers to recognize the breadth of knowledge and many different experiences their students bring into the classroom. An anti-racism teaching practice requires teachers to go deeper when getting to know their students and their backgrounds.

One way to bring in student's individual cultures is to employ the "funds of knowledge" concept presented by Moll, Amanti, Neff, and Gonzalez (1992). For example, by visiting students in their homes and learning about their unique situations, teachers are able to select curriculum activities that promote the participation of students in learning, even making them the experts in some situations. This practice can redefine typical classroom roles and privilege the students' knowledge and abilities. While "language educators must be acutely aware of the challenges of talking about culture in a way that does not reinscribe race ..." (Lee, 2015, p. 90), talking about culture is still important. Instead of focusing on dichotomies and cultural differences, teachers can help students recognize their similarities and small cultures (e.g. culture of basketball players or culture of music lovers) leading to positive identity formation and improved classroom culture. This strategy connects to Dlamini's (2002) presentation of identity as multi-layered, contradictory and fluid, and minimizes the risk of separatism and a "hierarchy of oppression" (p. 61). Examining funds of knowledge and the resources and abilities of households is also connected to Dei's (1996) tenth principle of antiracism education. This principle questions the practice of using the home environment as an explanation for the struggles some youth face in relation to schooling. Instead, "anti-racism education teaches that schools should be promoting effective student-teacher-parentcommunity interactions" (Dei, 1996, p. 35).

Another way to create positive relationships between schools, homes, and communities is by using students' language and culture as a bridge to success. Cummins (2002) states, "there are many ways to encourage students to use and explore their home languages or varieties of English in the classroom" (p. 29). One such way is through the use of identity texts. Identity texts allow students to bring their culture and lived experiences into the classroom. Often, students with limited English proficiency will write a personal text in their L1 and work with a more proficient same-language peer or volunteer to help them translate their text into English. This process allows students to convey their experiences and demonstrate their competency. By the end of the process, students have gained vocabulary, had the opportunity to build their identity, and helped strengthen their classroom community by sharing their narrative. Identity texts lead to positive identity investment by students, the perception that others value their culture, and collaborative relations of power that can be related to increased student success (Cummins, 2002). Dei's (1996) sixth principle of antiracism education clearly outlines how identity is related to success in school. Dei claims, "one task of anti-racism teaching is to help students make connections between their own self and the group they comprise" (p.32). Clearly, identity texts help fulfill this task. However, the use of identity texts can only be successful if teachers are willing to share power in the classroom, which is "one of the pillars of critical pedagogy" (Dlamini, 2002, p. 57). Without the willingness to allow students to explore their own narrative, the use of identity texts leads to further marginalization and oppression.

\section{Conclusions}


Although the EAL and TESOL community has begun work to move towards antiracism educational practices, they are not yet anti-racist. Both the community as a whole and individual educators have much to do before equity can be achieved for English language learners in Canadian K-12 schools. There is a need for educators to critically analyze teaching materials and curriculum, language policies, and the messages about English being communicated to students throughout the school. "An anti-racist teacher recognizes that students have a right to education that affirms their language and culture" (Mosley, 2010, p. 453). While that recognition is an important step, educators must also take action to implement critical pedagogy and anti-racism education.

EAL teachers must acknowledge the discrimination and racism their students face. However, more research related to EAL and linguicism is necessary to fully understand this issue. There is a gap in Canadian literature regarding the effect of racism and discrimination on ELL's academic success. Administrators, counsellors, and teachers often have lower expectations for students who are seen as minorities or ELLs, which results in these students being streamed to general or vocational programs instead of being placed on an academic track (Cummins, 1997; Zine, 2001). Simply skimming over these struggles will result in students disconnecting from the class and the subject material as illustrated by the case study of ten-year-old "Darren", an African-Canadian student provided with a Eurocentric curriculum delivered by White teachers resulting in limited participation in class activities, which he justified "on the grounds that they were boring" (Cummins, 1997, p. 422). What is seen by some as the ultimate insult is the placement of monolingual or native English speaking students in EAL classes, often based on the colour of their skin. Zine (2001) recounts examples of students born and raised in Canada and those who emigrated from English speaking countries who were placed in EAL due to "cultural variations of sociolinguistic style" or accentedness (p. 417). In some cases, these students lost out on academic opportunities that affected their ability to pursue post-secondary education.

As a White EAL teacher attempting to implement anti-racism education, I am caught in a paradox. In some ways, my position as a White EAL teacher does more harm than good. Taylor (2006) states, "White Anglophone TESOL [Teaching English as a Second or Other Language] and ESL [English as a Second Language] teachers need to recognize that [their] bodies are themselves part of the hidden curriculum, that they reinforce dominant images of English as a White language and of White native speakers as the most qualified teachers" (p. 540). However, my position as a White native English speaker also grants me the power and privilege to speak up for change. Becoming stuck in these contradictions will not benefit anyone. I must take action and "reject the idea that changing thoughts alone can disrupt racism" (Mosley, 2010, p. 467). Because my voice belongs to the group that has been deemed legitimate by many in society, I am able to speak out against the racism and discrimination English language learners face. I can use my voice to problematize the myth that North American and British English accents are superior, and English in general is inherently White. I can also use my position as an educator to share these ideas with my students and to privilege each voice of the English language learners in my classes.

Anti-racist EAL teachers must make a commitment to confront instances of racism. We need to speak out in staff meetings and lunchrooms to disrupt the systemic racism occurring in schools and bring anti-racism education beyond the walls of the EAL classroom. In addition, more work must be done to value, preserve, and strengthen heritage languages. 
Teachers have the ability to shape the social and educational goals that will be the focus of their classrooms. By placing ELLs' identity at the forefront of their planning and welcoming students' home language and culture into the classroom, teachers can begin the work of providing an anti-racist EAL program.

\section{References}

Armstrong, J. \& Ng, R. (2005). Deconstructing race, deconstructing racism. In Situating race and racisms in time, space, and theory: Critical essays for activists and scholars, 3045. Montreal QC: McGill-Queens University Press.

Bannerji, H. (1996). On the dark side of the nation: Politics of multiculturalism and the state of "Canada". Journal of Canadian Studies, 31(3), 103-128.

Bourdieu, P. (1986). The forms of capital. In J. G. Richardson (Ed.), Handbook of theory and research for the sociology of education (pp. 241-258). Westport, CT: Greenwood Press, Inc.

Bourdieu, P. (1991). Language and symbolic power (G. Raymond, M. Adamson Trans.). Cambridge, MA: Polity Press.

Coelho, E. (1998). Teaching and learning in multicultural schools. Bristol, PA: Multilingual Matters.

Cummins, J. 1997. Minority Status and Schooling in Canada. Anthropology and Education Quarterly, 28(3), 411-430.

Cummins, J. (2001). HER classic reprint: Empowering minority students: A framework for intervention. Harvard Educational Review, 71(4), 649-676.

Cummins, J. (2002). Beyond instructional techniques and standardized assessment: Implementing classroom interactions that foster power, identity, imagination and intellect among culturally diverse students. Contact, 28(2), 21-31.

Dei, G.S. (1996). Anti-racism education, theory and practice. Halifax, NS: Fernwood Publishing.

Dlamini, S. N. (2002). From the other side of the desk: Notes on teaching about race when racialised. Race Ethnicity and Education, 5(1), 51-66.

Henderson, J. \& Wakeham, P. (Ed.). (2013). Reconciling Canada: Critical perspectives on the culture of redress. Toronto, ON: University of Toronto Press.

James, C. E. (2009). 'It will happen without putting in place special measures': Racially diversifying universities. In F. Henry \& C. Tator (Eds.), Racism in the Canadian university: Demanding social justice, inclusion, and equity (pp. 128-159). Toronto, ON: University of Toronto Press. 
Kubota, R. (2015). Race and language learning in multicultural Canada: Towards critical antiracism. Journal of Multilingual and Multicultural Development, 36(1), 3-12.

Kubota, R., \& Lin, A. (2006). Race and TESOL: Introduction to concepts and theories. TESOL Quarterly, 40(3), 471-493.

Ladson-Billings, G. (1998). Just what is critical race theory and what's it doing in a nice field like education? International Journal of Qualitative Studies in Education, 11(1), 7-24.

Lee, E. (2015). Doing culture, doing race: Everyday discourses of 'culture' and 'cultural difference' in the English as a second language classroom. Journal of Multilingual and Multicultural Development, 36(1), 80-93.

Liggett, T. (2014). The mapping of a framework: Critical race theory and TESOL. The Urban Review, 46(1), 112-124.

Moll, L. C., Amanti, C., Neff, D., \& Gonzalez, N. (1992). Funds of knowledge for teaching: Using a qualitative approach to connect homes and classrooms. Theory into Practice, 31(2), 132-141.

Mosley, M. (2010). 'That really hit me hard': Moving beyond passive anti-racism to engage with critical race literacy pedagogy. Race Ethnicity and Education, 13(4), 449-471.

Motha, S. (2014). Race, empire, and English language teaching. New York, NY: Teachers College Press.

Taylor, L. (2006). Wrestling with race: The implications of integrative antiracism education for immigrant ESL youth. TESOL Quarterly, 4O(3), 519-544.

Skelton, C. (2014, July 8). ESL students in the majority at more than 60 schools in Metro Vancouver. The Vancouver Sun. Retrieved from http://www.vancouversun.com/health/students+majority+more+than+schools+Metr $\underline{\text { o}}+$ Vancouver/10005768/story.html

Smith, M. (2010). Gender, whiteness, and "other Others" in the academy. In S. Razack, M. Smith, \& S. Thobani (Eds.). States of race: Critical race feminist for the 21st century (37-58). Toronto, ON: Between the Lines.

Srivastava, S. (2007). Troubles with "anti-racist multiculturalism": The challenges of antiracist and feminist activism. In Hier, S.P. \& Singh Bolaria, B. (Ed.), Race and racism in 21st century Canada: Continuity, complexity, and change (pp. 291-311). Toronto, ON: University of Toronto Press.

Warburton, R. (2007). Canada's multicultural policy: A critical realist narrative. In Hier, S.P. \& Singh Bolaria, B. (Ed.), Race and racism in 21st century Canada: Continuity, complexity, and change (pp. 279-290). Toronto, ON: University of Toronto Press. 
Young, I. M. (1990). Five faces of oppression. Justice and the politics of difference (pp. 3965). Princeton, NJ: Princeton University Press.

Zine, J. 2001. Muslim youth in Canadian schools: Education and the politics of religious identity. Anthropology and Education Quarterly, 32(4), 399-423. 